\title{
Editorial
}

\section{Muscle function, Aging and Falls}

\author{
Yannis Dionyssiotis
}

Physical Medicine \& Rehabilitation Department, European Interbalkan Medical Center, Thessaloniki, Greece

All published work is licensed under Creative Common License CC BY-NC-SA 4.O (Attribution-NonCommercial-ShareAlike)

The treatment of osteoporosis which focuses only on bones ignores muscle function and balance elements connected to this disease, the prevention of falls and fractures ${ }^{1}$. Loss of balance leads to a fall: an uncontrolled involuntary downward movement in the direction of gravity with coming to rest on a deeper level ${ }^{2}$. It has to be counteracted by eccentric decelerating muscle action. The force we need for a movement against gravity is a summation of quickly released energy, which has been previously stored in elastic elements during (e.g. eccentric counter-movements), and currently generated muscle force by the actin-myosin-system ${ }^{3}$.

Aging leads to loss of muscle mass: sarcopenia is a geriatric syndrome with progressive loss of mass, quality and function of skeletal muscles associated with aging ${ }^{4}$. On the other hand fat mass and extracellular space increases with age and creates a passive mass, which does not contribute to strength or power ${ }^{5}$. Menopause has also been linked to a reduction in lean mass (and bone mineral density). Limitations in physical function during the perimenopausal and postmenopausal periods are common in women. However, whether their age, hormonal or other factors are related is controversial $^{6}$. There is debate about the positive association of muscle mass and estrogens, but the strength of evidence in support of an anabolic effect of estrogens on skeletal muscle via meta-analysis outweighs the evidence of no effect ${ }^{7}$.

\section{How can we measure muscle function, locomotion and risk of falling?}

A correct answer would be the quantification of typical daily movements. However, in the current literature muscle function is measured by various devices and described by concepts that often do not agree with the rules and terms of physics ${ }^{9}$.

From measurement of a particular muscle group, as is the case for grip strength, to time up and go test (TUG), Tinetti tests and Guralnik battery, which include some human subjectivity, and special maneuvers such as tandem walking, which uses dichotomous (yes/no) determinations, all these tests are useful to predict falls, hospitalization, sedentarism, immobilization and comorbidity etc $^{8}$. However, no single methodology ideally quantitatively evaluates this decline in muscle mass.
In the study of muscle performance, movement has to be described in terms of velocity and acceleration. Isometric force measurement methods have the drawback of measuring forces which do not reproduce the physiological movement. Isokinetic methods also have the limitation of motion at a given angular speed, so this situation is far from normal.

Force causes acceleration, i.e. we have to know the forces involved in movement. Each movement is the action of force along a distance in a certain time, and therefore measured as power ${ }^{3}$.

A modern technology called jumping mechanography (JM) may prove useful to quantitatively measure muscular function in older adults. JM appears to be a safe and potentially useful method to assess muscular function in older adults ${ }^{10}$. JM has also good test retest reliability compared with other tests ${ }^{11}$.

We need to take in mind that there are also some limitations to well-established and useful tests for risk of falls and balance. For example time up and go (TUG) test only contains basic movements of everyday life such as lifting, walking, turning, and the seatting but not striding over an obstacle that can lead to a fall. Most modern studies according to Falls prevention are also using other tests like six minutes' walk test (6 MWT) as a performance-based measure of functional exercise capacity in other populations ${ }^{12}$. Finally, gait is a complex motor behavior and besides proper motor facets (i.e. velocity) is linked to different aspects of cognition ${ }^{13}$.

\section{References}

1. Dionyssiotis $\mathrm{Y}$. Exercise in Osteoporosis and Falls Prevention. Athens: Monography (in Greek) published for Hellenic Institution of Osteoporosis (HELIOS) Hylonome Editions; 2008.

Corresponding author: Yannis Dionyssiotis, MD, PhD, Physical Medicine \& Rehabilitation Department, European Interbalkan Medical Center, 10 Asclepiou Str., Pylaia Thessaloniki, 57001 , Greece

E-mail:yannis_dionyssiotis@hotmail.com

Accepted 26 April 2016 
2. Lamb SE, Jorstad-Stein EC, Hauer K, Becker C, Prevention of Falls Network Europe and Outcomes Consensus Group. Development of a common outcome data set for fall injury prevention trials: the Prevention of Falls Network Europe consensus. Journal of the American Geriatrics Society, 2005;53(9): 1618-22.

3. Runge $M$ and Schacht E. Multifactorial pathogenesis of falls as a basis for multifactorial interventions. J Musculoskelet Neuronal Interact 2005;5(2): 127-134.

4. Roubenoff R. Sarcopenia and its implications for the elderly. Eur J Clin $\operatorname{Nutr}(2000) ; 54: S 40-S 47$

5. Runge M, Rittweger J, Russo CR, Schiessl H, Felsenberg D. Is muscle poweroutput a key factor in the age-related decline in physical performance? A comparison of muscle cross section, chair-rising test and jumping power. Clin Physiol Funct Imaging 2004;24(6):335-40.

6. Kurina LM, Gulati M, Everson-Rose SA, Chung PJ, Karavolos K, Cohen NJ, Kandula N, Lukezic R, Dugan SA, Sowers M, Powell LH, Pickett KE. The effect of menopause on grip and pinch strength: results from the Chicago, Illinois, site of the Study of Women's Health Across the Nation. Am J Epidemiol 2004; 160(5):484-91.

7. Dionyssiotis Y, Galanos A, Michas G, Trovas G, Lyritis GP. Assessment of musculoskeletal system in women with jumping mechanography.
Int J Womens Health 2010;1:113-8.

8. Buehring B, Krueger D, Fidler E, Gangnon R, Heiderscheit B, Binkley N.Reproducibility of jumping mechanography and traditional measures of physical and muscle function in older adults. Osteoporos Int 2015;26(2):819-25.

9. Runge M. Bad Liebenzell, Germany: International Society of Musculoskeletal and Neuronal Interactions, Black Forest Forum; May, 2006. Measurement of human movements by mechanography. Abstracts book.

10. Buehring B1, Krueger D, Binkley N. Jumping mechanography: a potential tool for sarcopenia evaluation in older individuals. J Clin Densitom 2010;13(3):283-91.

11. Rittweger J, Schiessl H, Felsenberg D, Runge M. Reproducibility of the jumping mechanography as a test of mechanical power output in physically competent adult and elderly subjects.J Am Geriatr Soc 2004;52:128-131.

12. Balke B. A simple field test for the assessment of physical fitness. REP 63-6. Rep Civ Aeromed Res Inst US 1963; 1-8.

13. Holtzer R, Verghese J, Xue X, Lipton RB. Cognitive processes related to gait velocity: results from the Einstein Aging Study. Neuropsychology 2006;20(2):2 15-23. 